\title{
Study on the Dilemma and Innovation Path of English Majors' Translation Teaching
}

\author{
Jianhua Jiang \\ Dongchang College Liaocheng University, Shandong Liaocheng 252000
}

Keywords: translation teaching methods; English teaching; multimedia technology

\begin{abstract}
The translation course is a compulsory course for students of English majors in colleges and universities, which plays an important role in cultivating students' innovative thinking ability and cross-cultural awareness. In recent years, the course has experienced the phenomenon of single teaching materials, outdated teaching modes and inefficient classroom teaching in the course of teaching practice. Reforming and innovating the traditional teaching model of translation courses is the key to solving these problems. This paper starts with the value of translation courses to cultivate the innovative thinking ability of English majors, analyzes and discusses the dilemma of translation courses in real teaching, and then proposes the teaching reform and innovative methods of translation courses, in order to benefit the translation teaching of English majors.
\end{abstract}

\section{Introduction}

At present, the textbooks used in the English professional translation courses are old and the content is simple. There are few opportunities for students to practice, and the knowledge and skills they have learned cannot be flexibly applied to practical operations. Translating talents cultivated through traditional teaching methods can no longer meet the needs of today's society for compound translators. In general, the status quo of translation teaching in colleges and universities is not satisfactory. Therefore, it is urgent to reform the teaching of translation, especially innovation in the translation course in accordance with the teaching methods of the times and social development.

\section{The Dilemma of Translation Courses in Real Teaching}

For a long time, the translation classroom is basically that a teacher teaches translation skills and students keep making notes. Students are always in a very passive state and accept "retelling" about translation skills. In addition, teachers tend to focus on the translation of words and phrases while neglecting the influence of cultural factors on text translation in teaching process. When dealing with text translation, they spend a lot of time on the interpretation of words and sentences. They do not regard the translated text as a complete unit of meaning, ignoring the understanding and expression of the text from a cultural perspective. Therefore, it is difficult for teachers to vividly interpret the content of the text, judge the pros and cons of the translation and the relevance of the translation. It does not help the students to improve their understanding of the nature and standards of translation, so the translation course has become a dry note class as a result.

Jiang Qiuxia, Cao Jin pointed out that at present, Chinese translation textbooks lack the hierarchical content of translation skills, lack the comprehensive structure of translation disciplines, ageing knowledge, subject matter, genre, lack real context, and lack cultural exchange characteristics of translation [1]. Zhang Meifang's survey of Chinese translation textbooks shows that $11.1 \%$ of people think that the existing textbooks have a single form of practice and lack reasonable matching, where examples of translation and practice are not widely available [2]. This phenomenon leads the students fail to access different styles of articles in the translation classroom. They have little knowledge of the linguistic features and styles of different styles. They cannot apply the translation techniques they have learned to the translation of different styles and texts. Therefore, this model can no longer meet the needs of today's society for composite and applied translation talents. 
The rapid development of multimedia technology is making profound changes in today's translation teaching and learning methods. The integration of multimedia technology and translation teaching has enabled the transition of teaching resources from a single use of paper text to a diversified form of "paper text + media materials". The traditional classroom teaching model centered on "teachers" is gradually being replaced by a new model of multimedia-assisted teaching. However, multimedia technology does not give full play to the advantages of network resource libraries and hypermedia links in translation teaching. Therefore, the translation course needs to use modern multimedia network technology to reform the existing classroom teaching mode, in order to improve the forward-looking and practical effect of translation teaching.

\section{Reform and Innovation of Teaching Methods in Translation Courses}

The teaching of translation courses is theoretical and practical. It is of far-reaching significance to take "the emphasis on both theory and practice" as the guiding ideology for constructing a scientific teaching model. This requires teachers to find the entry point of the combination of theory and practice, and systematically teach translation theory in the teaching. If the teacher chooses some translation theories arbitrarily to explain in the teaching, the theoretical points are out of line with the problems encountered by the students in the translation of the texts, and the students cannot deeply understand the guiding significance of the translation theory to practice. Students can first practice translation and find translation difficulties from actual combat training, then teachers explain relevant theoretical points in a targeted manner, that is, in accordance with the principle of "practice first, theory keeps up". In the translation class, the theory is to explain relevant theoretical points on the basis of students' translation practice to help students analyze and solve problems encountered in translation practice. Theory is both a teaching content and a teaching method, which helps students to improve their understanding of the nature and standards of translation and continuously improve their translation level.

In the teaching of translation courses, the corpus presents a large number of examples with real contextual meaning in the form of contextual co-occurrence. Creating a contextualized, realistic, and three-dimensional teaching effect can greatly enhance learners' knowledge and construction. Therefore, with multimedia technology to reform the teaching model of the translation course, we can first use multimedia technology to develop translation course resources. The diverse teaching resources of "paper text + multimedia materials" are the basis for translation curriculum reform. In addition to the overall development of the textbook, teachers can also use the modern network information and multimedia teaching information material library to produce translation courseware, and integrate the English and Chinese cultural resources in an intuitive and vivid way to increase the amount of information in language and culture.

Translation is essentially a process of information transmission. It involves not only two languages, but also the exchange of two cultures. It is not only the transformation of language forms, but also the transformation of ways of thinking. In the process of translation teaching, teachers teach the differences between English and Chinese in thinking mode and logical habits, help students solve the problems of language logic and thinking in the process of thinking mode conversion and language conversion, and help students improve their coping strategies. In the process of translation teaching, teachers should integrate the teaching of English and Chinese language and culture, and add the contrast between the two languages and cultures in the way of thinking, values and expression habits, which allows students to gradually understand the inherent differences between English and Chinese and the historical and cultural reasons for this difference. Teaching a translation course with a comparative teaching method enables students to learn to appreciate translation and truly appreciate the mystery of translation.

Teachers can use the "task-based" translation teaching model to develop students' ability of scientific inquiry and cooperation. In the "task-based" translation teaching practice, teachers can carry out the following activities: (1) provide the students with translation text, so that students can analyze and judge them in groups, and then the center spokesperson selected by each group will present to the class. The group discussion not only helps to enlighten thinking, improve the ability 
to analyze and solve problems, but also cultivate team spirit and competitive consciousness and scientific inquiry spirit. On the basis of the reports of the groups, the teachers commented and summarized the translations of the groups. (2) Independent translation and personal reporting. College students have strong autonomy and like to express their personal opinions. Therefore, after learning the theoretical basis of translation, translation skills, and having a certain understanding of the translation of the text, teachers can encourage students to complete the translation practice independently, and let some students make personal translations, give timely praise to good translations and point out the shortcomings. (3) Compare the student's translation with the reference translation. The teacher provides a reference translation that allows students to compare their translations with reference translations, and analyze the similarities and differences between the two translations in the Chinese and English sentence structure, the smooth flow of language, the reproduction of stylistic style and the appropriateness of logical thinking, so as to realize the translation and improve the translation consciousness.

\section{Conclusion}

Translation courses play an important role in cultivating students' intercultural communication awareness and innovative thinking ability. The traditional and old teaching mode does not adapt to the needs of the cultivation of compound translation talents in the new era. Therefore, the translation course needs to update the teaching concept, and apply modern information technology to develop and innovate teaching mode. The author believes that it has practical significance for the teaching of translation courses to integrate the translation theory into practice skillfully, to find the entry point of the combination of theory and practice, to develop curriculum resources with modern multimedia information technology and to reform the old teaching mode.

\section{References}

[1] Jiang Qiuxia, Cao Jin. The status quo of translation major construction: analysis and recommendations [J]. Chinese translation, 2006, (5).

[2] Zhang Meifang. Chinese-English translation of textbooks (1949 - 1998) [M]. Shanghai: Shanghai Foreign Language Education Press, 2001. 